\title{
Language learning and teaching - theory and practice
}

\section{Theory and principles}

\section{0-112 Beeching, Kate. Grammar is dead. Long live system-building? British Journal of Language Teaching, 27, 2 (1989), 95-8.}

The teaching of modern languages in Britain has benefited from theories and approaches in teaching English as a foreign language. Now that the communicative approach is well estaolished in many areas of TEFL, it is appropriate to ask whether we should follow the current return to grammar in EFL teaching. Grammar must be taught in different

ways according to the differing abilities and different levels of the learners. Above all, content must be meaningful. It is recommended that students be provided with authentic, even if imperfect, materials for learning how to comprehend, and with specially constructed materials for learning how to produce.

90-113 Besse, Henri (ENS Fontenay-Saint-Cloud-CREDIF). Hypothèse, la règle et la loi. [Hypothesis, rule or law?] Français dans le Monde (Paris), special number 2/3 (1989). 103-12.

1)iffering concepts of what constitutes grammatical rules have held sway in successive times: prescriptive, or grammar as a set of rules concerning correct behaviour as laid down by authority; descriptive, quasi-scientific laws deduced by linguists from study and observation, and constructivist, where the grammarian formulates hypotheses about the lanaguage, inventing rather than discovering rules. These different concepts imply different approaches to language and teaching methods.

In order to discover the preconceptions con- cerning grammar held by teachers of French as a second or foreign language, 264 teachers, half of them native speakers, were asked to fill in a questionnaire. Many gave conflicting and contradictory replies. Results showed that a 'mixed' descriptive - constructivist approach predominated over a prescriptive-descriptive one. Futhermore, there were indications that mother tongue and cultural background strongly influenced teachers' perceptions of grammar.

90-114 Galisson, Robert (U. of Paris III). Problématique de l'autonomie en didactique des langues (contexte français). [Problems of autonomy in language teaching theory in the French context.] Langue Française (Paris), 82 (1989), 95-118.

Linguistics and DDL (didactique des langues) are in the roles of coloniser and colonised; some historical and political explanations for this are offered and reasons given why DDL is asserting and should assert its independence. These reasons include the historical primacy of DDL, applied linguistics being a recent Anglo-American import; the focus of linguistics on the stable 'ideal speaker'; of DDL on the learner in a state of transition; the failure of the myth of scientific progress embodied in the audiolingual method; and the relevance of other fun- damental disciplines. Whereas a theory of teaching chemistry must be underpinned by a theory of chemistry itself, this does not apply to languages, because in learning chemistry there is no equivalent of natural acquisition.

A profile is offered of DDL as an autonomous discipline, borrowing from but not dependent on other disciplines, and including re-named or reconceptualised components, such as 'programmologie' for what was formerly called 'applied linguistics'. 


\section{0-115 Hoffmann, Lothar. Fachsprachenlinguistik und Fachbezogene}

Fremdsprachenausbildung: Positionsbestimmungen aus der Sicht der Leipziger

Schule. [The linguistics of foreign languages and language teaching for special purposes: the situation as seen by the Leipzig school.] Die Neueren Sprachen (Frankfurt am Main), 88, 5 (1989), 448-62.

Very close interaction and interrelation has long existed between linguistics and foreign language teaching in general, and between LSP research and LSP instruction in particular. Nevertheless, the principles of linguistics and didactics are not always in congruence with one another. The author of this paper discusses the antinomies of centralisation and pluralism, of unification and differentiation, of identity and specificity, of language system and speech activity, of structure and function, of (linguistic) description and (pedagogical) presentation, of professional competence and communicative proficiency. He proposes theoretical and practical solutions for their reconciliation and for co-operation between LSP linguists and LSP teachers.

\section{0-116 Ibrahim, Amr Helmy. Pourquoi tout ce savoir sur les langues? [What's} the point of all this knowledge about languages?] Études de Linguistique Appliquée (Paris), 74 (1989), 7-18.

The academic study of grammar and lexis is fraught with paradoxes. Scholars are interested in regularity and logic, but the most frequent words and constructions are irregular and not logically explainable. Dictionaries are judged on their treatment of common words like do, have, to, circle, but the words likely to be looked up by native speakers are different, and by non-natives different again. The value of traditional language descriptions is unclear, given that people can learn to speak and sometimes even write a language without exposure to such descriptions. One major motive for codifying language description is the prescriptive one, the desire to fix what is correct in language, but we must also take account of the constant tendency of language to evolve new forms.

The author recommends a contrastive approach to language description, emphasising those elements which are not the same even in closely related languages. These language-specific systems, referred to as noeuds (knots), can be found on both the lexical level (collocation) and the grammatical level (e.g. auxiliaries, pronouns). This approach requires of the teacher a perfect knowledge of at least two languages. [Brief examples from French, English, Italian, Arabic.]

90-117 Reeves, Nigel. 1992 and the linguist. Modern Languages (London), 70, 3 (1989), 131-9.

On the economic and industrial level, with the coming of 1992, transnational companies will only succeed against relentless competition if they are efficient in communication between plants and outlets, and also between their staff. Linguistic barriers will have to be crossed: a good manager has to be able to talk to his colleagues as real people, which means having access to their mother tongue. Europe will be an extremely diverse market (in terms of taste), rather than a single or common market, e.g. the food industry. It is not only managers, export directors and sales executives in UK-based companies who need foreign language skills; the beginning of a business transaction is often a telephone call or telex, so telephonists, receptionists and secretaries also need languages, likewise service and installation engineers.

When the directive for the recognition of diplomas comes into force (expected in 1991), over 80 professions not previously covered should obtain the right to practise throughout the community (including engineers, teachers and accountants). The service industries, perhaps even more than manufacturing, rely on accurate communication between client and professional, and an intimate understanding of cultural and systematic differences. Political integration can only occur through a mutual recognition and respect for different historical traditions, including those of minorities.

The inclusion of a foreign language in the foundation subjects for the National Curriculum is a historical step. Will the second foreign language be squeezed out? German is suddenly a shortage subject. We could be as many as 3000-4000 teachers short in languages, with the bulk in German.

A new set of specialist linguists supplementing the traditional professions of translator and interpreter will be needed. Computer tools will be developed to enable experts to build up their own multilingual glossaries and terminologies, term equivalences, etc. 
Working with computers will be a central requirement for those in the language industries. The new Europe offer linguists a great opportunity.
Changes will favour language teaching and should ensure recognition of the key importance of German.

\section{0-118 Weinrich, Harald (U. of Munich). Les langues, les différences. [Languages and their differences.] Français dans le Monde (Paris), 228 (1989). $49-56$}

With 4,000 or 5,000 languages spoken on earth there is a tendency to decry this proliferation and superfluity, though it is perfectly consonant with the differentiating prodigality of nature in other aspects. Difference should therefore be welcomed and embraced, particularly in the increasingly uniform world of European integration and multinational business. Whereas most inventions have been in the service of speed and greater efficiency, the opposite tendency obtains in languages, which cannot be learned significantly quicker than 3,000 years ago. Whereas material civilisation imposes a fast pace, culture, including language, imposes a slow one. To serve the demands of speed, a universal lingua franca is needed, viz. English, which, for practical rather than personal or nationalistic reasons, is far ahead of its nearest competitors, French and German.

However, this endangers other languages, and anglophones themselves, who risk falling into monoglossia and monoculture. To counterbalance this, language teaching should be trilingual, with English relegated to third place, allowing another foreign language to flourish. This will serve the more leisurely pace of culture. All languages are not equally foreign and each demands its own methodology and pace adapted to the learner group.

\section{Psychology of language learning}

\section{0-119 Benson, Malcolm J. (Hiroshima Shudo U., Japan). The academic} listening task: a case study. TESOL Quarterly (Washington, DC). 23, 3 (1989). $421-45$.

This article reports on an ethnographic research project that investigated an ESL student's actual listening activities during one academic course at a U.S. university. Having successfully entered the university following a period of ESL instruction, the (Arabic-speaking) student became a master's candidate. Examination of his notebooks, together with interviews and recordings of lectures, revealed that rather being preoccupied with the acquisition of new facts, he was engaging in a variety of processes relating both to the material and to the teacher. These processes involved the reduction of incoming linguistic data, the making of new connections within already familiar concepts, and an identification with the teacher's vicwpoints. The findings lead to the idea that content-based listening classes would be helpful in ESL preparatory programmes, and the guiding principles for the design of such courses are suggested.

\section{0-120 Bongaerts, Theo and Poulisse, Nanda ( $U$. of Nijmegen). Communication strategies in L1 and L2: same or different? Applied Linguistics (Oxford), 10, 3 (1989), 253-68.}

This paper sets out to explore similarities and differences in L1 and L2 referential communication. Some inadequacies in existing taxonomies of $\mathrm{L} 2$ communication strategies are pointed out and an alternative taxonomy is presented in which similar distinctions are proposed to the ones made in studies of L1 referential communication. An account of an experiment is given in which native speakers of Dutch had to describe, first in Dutch and then in English, a set of unconventional abstract shapes which have been used in a long series of studies of L1 referential communication initiated by Krauss and Weinheimer (1964). It is demonstrated that the referential behaviour of the subjects in both task versions can be described in terms of choices between two main strategies: subjects set out to describe the shapes from a holistic or a segmental perspective. In both task versions subjects exhibited a strong preference for holistic perspectives. Differences between the two task versions were mainly quantitative in nature. In particular, subjects needed much more time for the English version than for the Dutch version. 
90-121 Clahsen, Harald ( $U$. of Düsseldorf) and Muysken, Pieter ( $U$. of Amsterdam). The UG paradox in L2 acquisition. Second Language Research (Utrecht), 5, 1 (1989), 1-29.

There is a considerable amount of recent evidence that stable principles of Universal Grammar (UG) are available to adult second language (L2) learners in structuring their intuitions about the target language grammar. In contrast, however, there is also evidence from the acquisition of word order, agreement and negation in German that there are substantial differences between first language (L1) and L2 learners. In the authors' view, these differences are due to UG principles guiding L1, but not $\mathrm{L} 2$ acquisition. Alternative ways of accounting for the L1/L2 differences are not successful. Finally the authors deal with the question of how their view can be reconciled with the idea that $\mathrm{L} 2$ learners can use UG principles to some extent in the evaulation of target sentences.

90-122 Collier, Virgina P. How long? A synthesis of research on academic achievement in a second language. TESOL Quarterly (Washington, DC), 23, 3 (1989). 509-31.

To expand the current theoretical base in second language acquisition, this article proposes nine generalisations on optimal age, L1 cognitive development, and L2 academic achievement. These generalisations summarise the author's and others' research on second language acquisition for schooling purposes. In this synthesis, relationships among the following variables are considered : first language acquisition, second language acquisition, student age at the time of exposure to a second language, academic achievement (as measured by standardised tests in all subject areas), membership in a language majority or language minority community, and language(s) of instruction in school. The five new generalisations presented at the end of the article, which are based on academic achivement in a second language, merit additional research to validate and refine them.

\section{0-123 Cumming, Alister (U. of British Columbia). Writing expertise and second-language proficiency. Language Learning (Ann Arbor, Mich), 39, 1 (1989). $81-141$.}

The second-language writing performance of 23 young adults on three composition tasks was assessed in relation to their writing expertise and secondlanguage proficiency. Both factors accounted for large proportions of variance in the qualities of written texts and problem-solving behaviours in the second language. But the factors exerted independent effects, suggesting they are psychologically distinct. Writing expertise proved to relate to: qualities of discourse organisation and content in the compositions produced; attention to complex aspects of writing during decision making; problem- solving behaviours involving heuristic searches; and well-differentiated control strategies. Secondlanguage proficiency proved to be an additive factor, enhancing the overall quality of writing produced, and interacting with the attention that participants devoted to aspects of their writing. But secondlanguage proficiency did not visibly affect the processes of composing. In all analyses, more cognitively demanding argument and summary tasks produced significantly different behaviours from a less cognitively demanding letter task.

\section{0-124 Danesi, Marcel (U. of Toronto) and Mollica, Anthony (Brock U.) From right to left: a 'bimodal' perspective on language teaching. Canadian Modern Language Review (Toronto), 45, 1 (1988), 76-89.}

Early neurolinguistic research suggested that the left hemisphere of the brain was dominant and the seat of language, but it has now been shown that both hemispheres play major, but different, parts in language use. The left is associated with literal meaning, sequential relations, verbal memory, logical tasks, abstracting, text analysis; the right with connotation, spatial relations, visual memory, intuitive tasks, concretising, context and speech-act synthesis. Acquisition may be seen as a process of the right hemisphere, learning of the left.

The principle of 'modal directionality' suggests that teaching should flow, figuratively, from right to left. In the early stages the brain cannot absorb discrete categories (words, sentences, rules) and the emphasis should be on exploration and on creating 
schemata. The teacher can then 'shift modes' and use more formal, mechanical procedures.

In a class of beginners in Italian at the University of Toronto, 24 subjects were taught by such 'bimodal ' techniques, 21 by formalistic ('L-mode'), and 26 by mainly communicative ('R-mode') techniques. When tested, the bimodal group equalled the L-mode group in L-mode skills, equalled the R-mode group in R-mode skills, and outperformed both in the test overall.

\section{0-125 Davies, Eirlys and Bentahila, Abdelâli (Sidi Mohammed Ben Abdellah} U.. Fez, Morocco). On mother and other tongues: the notion of possession of a language. Lingua (Amsterdam), 78, 4 (1989), 267-93.

This paper explores the factors which may lead multilinguals to regard one of the languages they know as special to them, as when they feel able to describe a particular language as their own. It examines the varying and often conflicting and confusing ways in which the term 'own language' and some other familiar labels such as 'mother tongue', 'native language' and 'first language' have been used by laymen and specialists, and distinguishes a number of aspects of the relationship between an individual and a language which have been assumed to make it special. While discussions using such labels often imply that all these special qualities are usually combined in the same language, the paper presents data obtained from Moroccan informants of a number of different language backgrounds which suggest that this is certainly not necessarily the case. The language an individual considers to be his or her own is not always that which the objective outsider would predict; it need not be the language first learnt, that used in the home or with parents, that best known, or even one known at all. It is argued that overgeneralisations about the primacy of the mother tongue or the symbolic value of the native language may be dangerously misleading, for each individual may perceive the languages he or she knows in a unique way. It is oversimplistic to assume that there is any single condition whose fulfilment will always predict which language a multilingual will regard as his or her own.

90-126 Ely, Christopher $\mathbf{M}$. (Ball State U.). Tolerance of ambiguity and use of second language strategies. Foreign Language Annals (New York), 22, 5 (1989). 437-45.

This study developed a scale of tolerance of ambiguity (as an aspect of personality or cognitive style) related to second-language learning. The scale was used to discover if tolerance of ambiguity influences students' use of various second language strategies. The research was carried out with students of Spanish at university level. Multiple regression analysis provided partial confirmation of several specific hypotheses regarding tolerance of ambiguity. Strength of motivation, attitude, and concern for grade were also found to influence use of strategies.

\section{0-127 Eubank, Lynn (U. of Texas at Austin). Parameters in L2 learning: Flynn revisited. Second Language Research (Utrecht), 5, 1 (1989), 43-73.}

In a series of studies, Suzanne Flynn has proposed a specific theory with regard to Universal Grammar and second-language learning. The present study, a replication of the methodology and hypotheses in Flynn, utilises Arabic-speaking learners of ESL, who are predicted by Flynn's theory to perform much like her Spanish-speaking subjects. Present findings, however, contradict those of Flynn's work and, thus, cast doubt on her theory of Universal Grammar and L2 learning. Closer examination then reveals that the linguistic underpinnings of Flynn's theory in Huang have been superseded by the more recent analysis of Koopman, which does not support
Flynn's theory. Furthermore, certain assumptions on processing main and subordinate clauses (Townsend and Bever) and sentence anaphora (Carden; Reinhart), which have the capacity to predict Flynn's findings, also fail satisfactorily to predict the results from the speakers of Arabic. Finally, an analysis that predicts a failure of parsing under certain conditions is presented and found to predict the present findings with a high degree of accuracy. However, the paring analysis must be subjected to further study with an aim toward falsification before it can be assumed to be conclusive. 
90-128 Genesee, Fred and others (McGill U.). Three elementary-school alternatives for learning through a second language. Modern Language Journal (Madison, Wis), 73, 3 (1989), 250-63.

Since its inception in Quebec some 25 years ago, the immersion approach in a variety of forms has proved effective. Its success has been attributed both to its instructional features and to the fact that the participating students are members of majority ethnolinguistic groups, who do not feel their home language and culture threatened by immersion in a second language and culture. Three second-language learning programmes for English-speaking majority language students in Montreal are compared here: an early total immersion programme (first three years' curriculum instruction completely in French); a delayed immersion programme (French taught as a foreign language in initial years, rising to some 60 per cent of instruction later); and all-French schooling, albeit in a school with 85 per cent native English-speaking pupils. In effect, the all-French schools might be regarded as 'super immersion' programmes, especially as instructional strategies were observed to be similar.

Three questions guided the research. What are the advantages to second-language proficiency associated with extended second-language instruction in the absence of significant peer contact in the target language? What are the relative benefits to second-language achievement of an early and a delayed start? What are the effects, if any, on firstlanguage development of delayed and greatly reduced instruction in the first language? Four groups of grade five students participated, one from each type of programme, plus a group of French control students. On the first point, the researchers found that the anglophone students in all-French schools (called the Experimental or E1 group) and the early immersion students scored as well as the French control students on a number of the tests. It had been predicted that the Experimental students would achieve higher levels of proficiency because of their greater exposure to French. To test whether their proficiency was being hindered by the lack of substantial opportunity for peer interaction in the second language, the researchers then collected data on anglophone students (E2) attending the same classes as the French control students, where exposure to such peer interaction was inevitable. The E2 students scored consistently higher than E1 on almost all of the oral tests, but at the same level on written tests. The authors' second question, that of early versus delayed instruction, was not answered unequivocally by their findings. On the third point, the results provided further support for the wellestablished finding that majority language students do not suffer setbacks to their first-language development as a result of immersion in a secondlanguage school programme even when only minimal formal instruction in the first language is provided.

\section{0-129 Gropen, Jess and others (Massachusetts Inst. of Tech.). The learnability} and acquisition of the dative alternation in English. Language (Baltimore, Md), 65, 2 (1989), 203-57.

The dative alternation poses a learnability paradox: when children hear give money to him and give him money, they could formulate a rule deriving the double object from the prepositional form, but the rule would allow overgeneralisation from donate money to him to *donate him money. Children are not corrected for speaking ungrammatically, so how do they avoid overgeneralising? The 'conservatism' hypothesis proposes that children do not generalise at all; the 'criteria' hypothesis holds that children learn to constrain their rule to apply to monosyllabic verbs denoting possession changes. In a questionnaire study, adults rated double-object forms with novel verbs as sounding better if they met these criteria. In an analysis of speech transcripts, children were found to produce ungrammatical double-object sentences (though not very frequently). In two experiments children were taught novel motion verbs; they extended them to double-object structures, and did so more often for monosyllabic than for polysyllabic verbs and more often to denote a possession transfer than motion to a location. However, children also had a bias to use each verb in the construction they heard it in. Thus children are not invariably conservative but show conservative tendencies, and their generalisations are influenced by morphophonological and semantic criteria. It is proposed that speakers acquire a dative rule that operates on two levels: a broad-range rule defines the possibility of a verb meaning 'cause to move' to be changed into one meaning 'cause to have', and narrow-range rules license such extensions to be made for subclasses of semantically and morphologically similar verbs. 
90-130 Koda, Keiko (Ohio U.). Cognitive process in second language reading: transfer of $L 1$ reading skills and strategies. Second Language Research (Utrecht), 4, 2 (1988), 133-56.

Two crosslinguistic experiments were conducted with 83 skilled readers from four contrasting $\mathrm{L} 1$ orthographic backgrounds. Experiment 1 tested the effects of blocking either visual or sound information on lexical decision-making. Experiment 2 examined the effects of heterographic homophones (e.g. eight and ate) on reading comprehension. Data from the two experiments demonstrate that the subjects utilise cognitive skills and strategies developed in their L1 when reading English as an L2, suggesting that (a) L1-L2 cognitive process transfer does take place in L2 reading and also that (b) orthographic structure exerts a significant influence on cognitive processes in reading.

\section{0-131 Kraemer, Roberta and Zisenwine, David (Tel Aviv U.). Changes in attitude toward learning Hebrew in a South African setting. Language Learning (Ann Arbor, Mich), 39, 1 (1989), 1-14.}

This study investigated attitudes toward secondlanguage learning over an extended period of time in a cross-sectional design. Subjects were 1,252 children in grades 4 through 12 studying Hebrew in a private Jewish school system in South Africa. Five sets of attitudes were measured: attitudes toward learning the language, traditional orientation, nationalist orientation, motivation, and self-rating of proficiency. Results showed that attitudes decreased in positive value over the nine grade levels, although not always in totally linear fashion, supporting other research findings. The sharpest changes took place from Grades 4 through 9 while a less consistent pattern characterises the high-school years. The rate of decline was not equal for all attitude sets suggesting the need for different explanations to account for the variety of attitude patterns.

90-132 Myers, Marie J. Apprentissage d'une langue seconde: principales causes d'échec. [Learning a second language: main reasons for failure.] Canadian Modern Language Review (Toronto, Ontario), 45, 2 (1989), 241-4.

A lack of knowledge of the psychology of learning is believed to be the underlying reason for failure in second language learning. The highest cognitive step is not given the attention it requires. Classroom practice usually covers the areas of reproduction and most areas of conceptualisation, including recognition of the categories to which language elements belong, as well as recognition of relations between these elements and whether or not they are acceptable. Learners are also required to practice applying principles, either in exercises or situations related to the items taught. Where insufficient time is spent is in the area of 'mobilising materials', that is combining previously learned operations in other contexts and in the area of 'inventing' in a personal way in a totally new life situation for the learners. The question which remains unanswered is whether or not an institutional setting will allow for the very last phase to be completed or whether an immersion programme should become the mandatory complement of any second language programme.

90-133 Oxford, Rebecca L. ( $U$. of Alabama). 'The best and the worst': an exercise to tap perceptions of language-learning experiences and strategies. Foreign Language Annals (New York), 22, 5 (1989), 447-54.

This article presents an exercise useful for tapping perceptions of participants' best and worst languagelearning experiences and the strategies these individuals used in such experiences. Informal results across six training sessions are presented. Positive language-learning situations stimulated the use of a wide range of learning strategies, while negative situations stunted strategy use, restricting it mainly to strategies that helped learners cope with their day-to-day struggle with the dysfunctional environment. Possible future uses of 'the best and the worst' exercise with students, as well as for teacher training, are discussed. 
90-134 Oxford, Rebecca ( $U$. of Alabama) and Nyikos, Martha (Indiana U.) Variables affecting choice of language learning strategies by university students. Modern Language Journal (Madison, Wis), 73, 3 (1989), 291-300.

Variables affecting students' choice of learning strategies are discussed. This investigation is the largest completed study of language learning strategies, defined as the methods by which learners aid the acquisition, storage and retrieval of information. Good learners use a variety of strategies, such as guessing unknown meanings and interacting with others.

Some 1,200 foreign language students, mainly undergraduates, including approximately equal proportions of men and women, participated in the study. The Strategy Inventory for Language Learning (SILL), which asks learners to report the frequency with which they use certain language learning strategies, was used. The findings are summarised. Five main factors emerged: formal rule-related practice strategies were highly used; practices such as attending foreign films or talking with native speakers were least used; independent use of foreign language material was relatively little used; techniques such as studying hard were used at moderate to high frequency levels; and conversational techniques (such as regarding slower speech) were used moderately often. The second research question asked which variables affected choice of language learning strategies. The degree of expressed motivation most influenced the choice of strategies. Another strong influence was the student's sexwomen more frequently used conversational strategies. Other important variables were language proficiency self-ratings, the number of years spent in study, and whether the students themselves decided to take a course.

\section{0-135 Pienemann, Manfred ( $U$. of Sydney). Determining the influence of instruction on L2 speech processing. AlLA Review (Madrid), 5 (1988), 40-72.}

There is a set of universal speech processing constraints which applies to all types of second language acquisition. These constraints define the range of possible hypotheses about the structure of the L2 which a learner can create at a given stage of development, and they cannot be overrriden by formal instruction or by other alterations in the linguistic input.

This paper examines formal language learning from the perspective of language development in order to demonstrate that the speech processing factors constraining the learning process are the same as in other types of language development. To this end the stages of acquisition found in a longitudinal study on the formal acquisition of German as a Second Language (GSL) are compared with the stages found in natural GSL acquisition. Both sets of data are then used to test the predictions for stages of acquisition made by a set of universal speech processing factors.

\section{0-136 Polomska, Margaret (U. of Liverpool). A case for 'acquisitional} strategies': some methodological observations on investigation into second language learners' initial state. Second Language Research (Utrecht), 4, 2 (1988), 110-32.

This article reports on a pilot investigation into initial assumptions of second language learners in the methodological framework of 'acquisitional strategies'. Its focus is predominantly methodological, but experimental data is used to illustrate the approach. Acquisitional strategies constitute an elaboration of recent applications of the parameter setting model of grammar to the investigation of second language learners' initial state in that in this framework markedness and parameter setting interact with cognitive and psycholinguistic factors. Acquisitional strategies are understood as an identifiable, but subconscious plane according to which acquisition is handled and which is based on a subconscious assumption or a range of assumptions about the linguistic characteristics of the language under acquisition. Learners' initial state or their assumptions are seen as reflected empirically by a range of interacting formal and substantive choices, attached to a particular grammatical phenomenon. In contrast to the parameter setting model, the analysis of second language learners' initial state in the context of acquisitional strategies is essentially individual-based.

An exploratory application of this framework to the investigation of second language learners' initial state has been undertaken in the context of acquisition of preposition stranding by English learners of Dutch. Preposition stranding refers to a marked phenomenon where movement extracts an NP complement of the preposition out of PP, leaving the preposition 'stranded' behind. The respective realisation of this phenomenon in English and Dutch manifests interesting syntactic and 
morphological contrasts, which render it a valuable empirical tool for evaluation of acquisitional strategies. A tendency to statistically significant individual choices has been noted in this study. The predominant choice, manifested by the subjects, appears to be a strategy associated here with the assumption of non-equivalence of the phenomenon of preposition stranding in English and in Dutch.

\section{0-137 Porte, Graeme (U. of Granada, Spain). Poor language learners and their} strategies for dealing with new vocabulary. ELT Journal (Oxford), 42, 3 (1988), 167-72.

The analysis of structured interviews with 15 underachieving EFL learners in private language schools in London demonstrated that these learners were using strategies for dealing with new vocabulary which were very similar to those found in studies of 'the good language learner', such as overt and covert use of repetition in vocabulary learning, the writing out of translation equivalents in order to aid learning, and the use of dictionaries to discover meaning. Under-achievers however, demonstrate less sophistication and a less suitable response to a particular activity than 'good learners'. Many learners transfer learning strategies picked up at school or from other students across different (inappropriate) learning situations. They feel frustrated by new methods which do not fit in with their learning strategies. Some learners undervalue their own way of approaching an activity because they feel their teacher would not approve of it.

Teachers can help under-achieving EFL learners to identify, develop and refine their strategies. Students in class can compare their approach with that of other students, and see how other strategies might supplement their current behaviour.

90-138 Poulisse, Nanda and Schils, Erik (U. of Nijmegen). The influence of task- and proficiency-related factors on the use of compensatory strategies: a quantitative analysis. Language Learning (Ann Arbor, Mich), 39, 3 (1989), 15-48.

The study described in this paper was set up to investigate the effect of foreign language learners' proficiency level on compensatory strategies used by these learners to solve lexical problems. At the same time, the effect of task-related factors on compensatory strategies was examined. The study involved three groups of Dutch learners of English at three different proficiency levels. The subjects were tested on three different tasks: a picture naming/description task, a story retell task, and an oral interview with a native speaker of English.

It appeared that 'proficiency level' is inversely related to the number of compensatory strategies used by the subjects: the most advanced subjects used fewer compensatory strategies than did the least proficient ones. Contrary to expectations, however, the type of compensatory strategy chosen by the subjects was not to any large extent related to their proficiency level. Rather, the data indicate that task-related factors play a large role in this respect. Whereas the subjects predominantly used analytic strategies in the picture naming/description task, they frequently resorted to holistic strategies and transfer strategies in the story retell task and the oral interview.

To explain these differences it is suggested that in selecting compensatory strategies the subjects observed general conversational principles.

\section{0-139 Ricciardelli, Lina A. and others ( $U$. of Adelaide). Metalinguistic} awareness as a unitary construct, and its relation to general intellectual development. Rassegna Italiana di Linguistica Applicata (Rome), 21, 1/2 (1989), 19-40.

The notion that metalinguistic awareness can be conceived as a unitary construct was investigated using factor analysis. Ten metalinguistic tasks and 12 standard tests of intellectual development were studied in five- and six-year-old children, using factor analysis. The results supported the notion of 'a general metalinguistic ability'. Furthermore, the results suggested that metalinguistic awareness can be viewed as developing cocomitantly with other intellectual activities. However, a distinction was made between two types of metalinguistic tasks, associated with greater or less impact of schooling and maturation. 
90-140 Robert, Jean-Michel (U. Catholique de I'Ouest, France). Intralanguage. agrammatism and the conceptual system. IRAL (Heidelberg), 27, 3 (1989), 217-21.

This article considers the analogy between motor aphasia (agrammatism) and interlanguage. Interlanguages (in their intralinguistic components) and agrammatism apparently involve a logical reduction of morphology and syntax; in effect, a compensatory sub-system is developed to cope with communicative needs and linguistic limitation.

The author describes some of the main characteristics of agrammatism, e.g. the omission of articles, prepositions and personal pronouns as well as the use of telegraphic speech (i.e. primitive sentence structure and isolated nouns). Agrammatic patients can repeat single words and name objects, but demonstrate reduced fluency through use of excessive repetition. Verbs are uttered in the infinitive form. Agrammatic phenomena do not represent memory loss, but a deliberate reduction/simplification strategy. Intralanguage [sic] shares some of these features, particularly in the use of a simplified grammar.

Agrammatics and interlanguage speakers rely on the conceptual/semantic/thematic systems of a language, rather than on the grammatical, 'computational' aspects. In language acquisition, the conceptual precedes the computational, and the understanding of deep structure comes before the deployment of surface forms.

\section{0-141 Saleemi, Anjum P. (Allama lqbal Open U., Islamabad, Pakistan). Inputs} for L2 acquisition. IRAL (Heidelberg, FRG), 27, 3 (1989), 173-91.

The precise extent to which language input is causally sufficient in second-language acquisition is in dispute. The initial problem is one of definition; any notion of what constitutes input will reflect some prior theory of language. Reference is made to those forms of input (e.g. 'motherese' and 'foreigner talk') specifically modified for the learner.

Three major approaches to input are analysed. They differ in their emphases: innate linguistic capacities, external language input and conversational interaction have each been advanced as the vital factor in language acquisition. Despite their different perspectives they are presented here as components of a single comprehensive framework.
Second-language acquisition is considered to be a modular process: particular explanations may be more pertinent to some aspects of language than others. Our understanding of how input is transformed into output remains incomplete, however, while we lack an account of the neuropsychological processes involved. A partial explanation may be found in the human information-processing system, to which we do have some access. The strengths of an information-processing model of secondlanguage learning are recognised, and the role of external input is seen as a joint function of this system and inherent linguistic capacities.

\section{0-142 Schneiderman, E. I. and Desmarais, C. (U. of Ottawa). The talented} language learner: some preliminary findings. Second Language Research (Utrecht. The Netherlands), 4, 2 (1988), 91-109.

'Talent' as distinct from 'aptitude' is defined here as an exceptional ability to achieve native-like competence in a second language after puberty, manifested by possibly five per cent of the adult population. The neuropsychological substrate for talent in second-language learning can be described in terms of greater neuro-cognitive flexibility for talented than for untalented learners. Because children have no prior knowledge of the language they are about to acquire, they are maximally flexible, and it may be that talented adult language learners are able to arrive at accurate representations of second-language grammars because they too possess this flexibility and can avoid processing second-language input via cognitive pathways established for handling the first language. Providing direct evidence of neurocognitive flexibility in adults is an extremely difficult task, but the authors propose and test the following hypotheses: (1) that talented learners will perform memory tasks without necessarily relying on a strategy of categorisation, and will be exceptionally adept at acquiring new codes; (2) that they, unlike the majority of the population, will not be left-lateralised for language; (3) that the right hemisphere's appropriation for language functions may affect performance in others, so talented learners will perform better on verbal than nonverbal tasks; that they will exhibit factors from the 'Geschwind cluster', which can include migraines, schizophrenia, fair complexion, left-handedness, twinning, asthma and allergies.

Two subjects, one of each sex, were chosen for having achieved native-like proficiency in at least one language after puberty (age 11). Both were 
native speakers of English whose second language was French. In memory tests, neither relied on a conventional strategy of categorisation and, as predicted, both were adept at acquiring new codes. Both had a higher percentage of correct scores in the left ear than in the right ear on two dichotic listening tests, indicating that they are not left- lateralised for either French or English. As expected, their performance was better on verbal than nonverbal tests. The subjects and their families exhibited a number of characteristics from the Geschwind cluster, including sinistrality, allergies, schizophrenia and albinism.

\section{0-143 Tenjoh-Okwen, Thomas (ENS U. of Yaounde, Cameroon). A framework for describing interlanguages in multilingual settings. British Journal of Language Teaching, 27, 2 (1989), 88-94.}

Analyses of foreign language learners' interlanguages have assumed bilingual settings; these are inadequate when applied to learners with multilingual backgrounds. A framework for such study is presented. A language component takes into account the languages spoken by the learner and a curricular component describes the relative roles of formal and informal learning situations in determining the learner's intake. An important consideration is the extent to which speakers' languages other than their mother tongue contribute to their interlanguage. A base language hypothesis is advanced as a way of reducing practical difficulties inherent in such an undertaking. The base language is considered to be the language known to the learner which most closely resembles the language being learnt; it is from this language that transfer takes place, and which is considered to influence the interlanguage more than the mother tongue. Finally, environmental and cultural variables are delineated as important factors in foreign language learning.

90-144 Thomas, Margaret (Harvard U.). The acquisition of English articles by first- and second-language learners. Applied Psycholinguistics (New York), 10, 3 (1989). 335-55.

Child first-language (L1) learners frequently use the definite article in referential indefinite contexts, that is, with nouns appearing in the discourse for the first time, where adults use the indefinite article. Adult second-language (L2) learners also overgeneralise the definite article. Research reported here shows 30 L2 learners use the in referential indefinite contexts at significantly higher rates than in nonreferential contexts. Thus, both L1 and L2 learners may share an initial hypothesis associating the with referential nouns. This evidence of a strategy common to L1 and L2 learners invites reinterpretation of both $\mathrm{L} 1$ and $\mathrm{L} 2$ acquisition data.

90-145 Weltens, Bert and others ( $U$. of Nijmegen). The long-term retention of French by Dutch students. Studies in Second Language Acquisition (Bloomington, Ind), 11, 2 (1989), 205-16.

The present study investigated the retention of school-learned French language skills in Dutch students across a period of four years following the training period. Two training levels were investigated: four and six years of French training. The skills tested were all receptive: general receptive proficiency; listening and reading comprehension; and receptive phonological, lexical, and gram- matical skills. In addition, self-assessment measures were administered.

The results indicated that global skills improved, if anything, and that only lexical and, particularly, grammatical skills 'attrited' during the period investigated. On the other hand, subjects' selfperception of their retention was much more negative.

\section{0-146 Zobl, Helmut (Carleton U.). Modularity in adult L2 acquisition. Language Learning (Ann Arbor, Mich), 39, 1 (1989), 49-79.}

Modular conceptions of the language faculty assume that linguistic knowledge is encoded in distinct cognitive systems differing in the nature of their representations. Earlier investigations have reported that L2 (English) syntactic forms are adapted to L1 (Chinese/Japanese) discourse functions, which sug- 
gests evidence for module-sensitive acquisition. These findings invite a consideration of modular functioning in adult acquisition as a source of interlanguage-primary language differences. Drawing on these earlier findings and production data from a large written corpus of Japanese-English interlanguage, the paper shows that discoursepragmatic markedness conditions on the subject position combine with central aspects of a configurational syntax in the generation of sentential forms. The modular interaction leads to overrepresentation of NP-movement and extraposition constructions, a significant number of which violate the Theta-Criterion. Three positions on modular functioning are identified as possible ways of accounting for interlanguage-primary language difference: (1) partial loss of the domain-specific module; (2) penetration of the domain-specific module by external knowledge representations; and (3) the creation of a module interface distinct from the L1 and the L2. The data strongly support the third position, lend some support to the second, but are difficult to reconcile with the first.

\section{Research methods}

90-147 Allen, Patrick and others (OISE, Canada). Analytic and experiential aspects of second language teaching. RELC Journal (Singapore). 20, 1 (1989). $1-19$.

Referring to the Stern (1978) p-scale, 'analytic' is defined as tending to the formal learning end of the scale and 'experiential' to the functional end. Related learning dichotomies are discussed and previous research reviewed. The contrasts depend on degrees of emphasis rather than absolute differences between classrooms.

Then follows a description and discussion of the scheme for observing French language classrooms Communicative Orientation of Language Teaching (COLT), designed to measure features of communication typical of classroom discourse. This enabled the team to identify differences between programmes but not state which features were most beneficial. It was then applied to the learning outcomes of eight core French grade II classes in Toronto, which were ranked on a scale from most experiential to most analytic. This was contrasted with outcomes on an immersion course, which tends to be near the opposite, experiential pole. The methodology of each study is described and the background research discussed.

It is concluded that: (1) the analytic and experiential foci tend to be complementary and support each other, (2) the quality of instruction is important to both, and (3) learners may benefit if form and function are more closely linked. No tables of data are provided.

\section{0-148 Cumming, Alister (U. of British Columbia) and Swain, Merrill (Ontario Inst. for Studies in Ed.). Anecdotes of accidents: second language research going awry and telling us why. Second Language Research (Utrecht). 5, 1 (1989), 74-87.}

Internationally recognised experts in secondlanguage research were asked to provide anecdotes documenting memorable incidents where something had gone awry in their research. The anecdotes proved to emphasise problems of a technical, conceptual, or political nature. Fifteen anecdotes representing these three kinds of problems are presented. In common, the anecdotes express concerns for scientific realism, that is, second language research was said to go wrong in cases where legitimate claims for knowledge were undermined - by accidents, unforeseen intrusions, or misconceptions. This view of constraints on secondlanguage research, based on researchers' experiences (rather than theoretical polemics or methodological prescriptions), may be valuable for learning researchers, users of research results, and critical analyses of second-language research processes.

\section{0-149 Swaffar, Janet K. (U. of Texas). Competing paradigms in adult language acquisition. Modern Language Journal (Madison, Wis). 73, 3 (1989), 301-14.}

Thirty years ago the language standard was langue, the language norm of a speech community, its grammatically perfect sentences, whereas today the standard is parole, appropriate expression within a specific speech community, including the prag- matics of contextually defined situations. This radical shift in perspective has ushered in new methods and goals of second-language teaching in the United States, as well as new research methods. Once the learner becomes the focal point of the 
research, the effects of a host of learner variables (different language backgrounds, maturational levels or motivations) recommend themselves as design features. Interlanguage research illustrates the shift away from contrastive analysis of learner performance measured against a correctness norm, to analysis of performance as a series of learning stages.

But despite lip service paid to the new paradigm, classroom reality is still far from the learner-centred definitions of language instruction. Current teaching and asessment practices may in fact defeat communicative objectives. Although the author applauds the launch in the 1980s of the ACTFL proficiency movement, and its testing programme which defines language acquisition as stages in learner linguistic development paralleled by learner ability to express cognitive capacity, she also points to its shortcomings and urges constructive debate about future changes. She would also welcome changes in research design to allow (a) further exploitation of existing research findings (because variables play such an enormous role); (b) closer ties with teachers and, since second-language research is based very largely on first-language models, with experts in artificial intelligence and cognitive psychology; (c) assessment of dominant learning models; $(d)$ investigations of how the adult language learner's acquisition ability is modified. With research emphasis on proficiency testing, it should not be forgotten that the language classroom still needs effective models for testing material studied in class. Teachers need to know how to use the insights of affective and strategy research to design tests that reflect and encourage creative, communicatively orientated strategies on the part of the students.

\section{Testing}

\section{0-150 Alderson, Charles J. (U. of Lancaster) and Lukmani, Yasmeen}

(Bombay $\cup$.). Cognition and reading: cognitive levels as embodied in test questions. Reading in a Foreign Language (Oxford), 5, 2 (1989), 253-70.

Various lists of reading skills are proposed in the literature. It has frequently been asserted, or implied, that these skills can be ranked hierarchically, from 'lower' to 'higher' order skills. In this study, teachers at Lancaster University were presented with a reading test used at Bombay University and required, among other tasks, to rate the items as tests of 'lower', 'middle', or 'higher' order abilities. In 27 out of 41 items, there was little agreement between judges. An item analysis of the performance of students at Bombay University was carried out on the remaining 14 items, on which agreement had been reached. This showed that there was little relationship between level of item difficulty and the supposed level of comprehension. Discrimination was largely achieved by the lower order items. Some possible implications for the testing of language and reading are put forward.

\section{0-151 Arnaud, Pierre J. L. (U. Lumière-Lyon II). L'évaluation communicative: principes et problèmes. [Communicative evaluation: principles and problems.] Langues Modernes (Paris), 38, 5 (1989), 51-63.}

This critical survey compares communicative tests appearing since 1980 under the influence of Munby and B.J. Carroll with psychometric-structuralist tests appearing from 1960 in the tradition of Lado. Communicative tests have a superior theoretical basis, aiming to test use not usage, relating to global tasks in authentic situations, and stressing construct and content validity. Direct measurement of the target behaviour and hence criterion-referencing are possible. But problems include higher cost and less objective marking, whilst authenticity is also an elusive concept, as any test is in some sense artificial, and the author doubts Carroll and Hall's claim that their kind of test is enjoyable and user-friendly. The lack of an agreed inventory of functions, skills, etc., also makes criterion-referencing problematic. The author pleads for an eclectic approach in which both kinds of test have a place.

90-152 Bachman, Lyle F. (U. of Illinois) and Palmer, Adrian S. (U. of Utah). The construct validation of self-ratings of communicative language ability. Language Testing (London), 6, 1 (1989), 14-29.

The trait structure of an experimental self-rating test of communicative language ability was investigated through the use of MTMM design and CFA procedure. The language abilities the authors attempted to measure comprised three main traits: grammatical competence, pragmatic competence, 
and socio-linguistic competence. Three different question types were used. The subjects were 116 non-native English speakers from the Salt Lake City area. The results of this study indicate that selfratings can be reliable and valid measures of communicative language abilities. The obtained reliabilities were much higher than had been expected, and all the self-rating measures had strong loadings on a general factor. In addition, some measures proved to be reasonably good indicators of specific language abilities. The measures of grammatical competence appear to be better indicators of this trait than are the measures of pragmatic and sociolinguistic competence. Of the three question types used, the most effective appears to be that which asked about subjects' perceived difficulty with various aspects of the language. The least effective question type was the so-called can-do question.

\section{0-153 Gonzalez Pino, Barbara (U. of Texas at San Antonio). Prochievement testing of speaking. Foreign Language Annals (New York), 22, 5 (1989), 487-96.}

Today's language teacher emphasises, among other things, the development of students' oral skills. Therefore, many teachers are seeking or innovating ways to test the speaking skill while (1) overcoming perennial problems such as the lack of time and the subjectivity of grading, and (2) finding effective ways of making achievement testing more proficiency oriented. The author presents a practical oral testing model which she researched, developed, implemented, disseminated, piloted and refined in a variety of middle school, secondary, and university settings in Texas over the past six years.

The author presents an outline of the principal considerations involved in establishing an oral testing programme and covers a range of options under each heading. Major concerns discussed include: fitting speaking tests into the syllabus and course grade, linking teaching and testing approaches (with sample formats), testing interactive and individual performance, new versus old material, and impromptu versus prepared performance. Also covered are: sample size, scoring at various levels (with sample scales) partnering procedures, the role of tapes, scheduling, planning (with sample guide), and predicted outcomes.

90-154 Hale, Gordon A. (Educational Testing Service) and others. The relation of multiple-choice cloze items to the Test of English as a Foreign Language. Language Testing (London), 6, 1 (1989), 47-76.

Four categories of multiple-choice (MC) cloze items were examined in relation to the TOEFL. The object was to assess the factor structure of the TOEFL and the potential of distinguishing MC cloze items aimed at reading comprehension (defined in terms of textual constraints ranging across clauses) as contrasted with knowledge of grammar (short-range surface syntax and morphology) or vocabulary. Since it is impossible in principle to distinguish such skills absolutely at any given point in a text, a compromise was to identify items whose difficulty seemed to be based primarily on one level of processing and secondarily on another. The pivotal category was reading comprehension. In all, $50 \mathrm{MC}$ cloze items over three texts were used in four subsets: ones for which reading comprehension seemed to be the primary source of difficulty, and (1) grammar secondary or (2) vocabulary secondary (nine and 14 items respectively); and ones for which either (3) grammar or (4) vocabulary was the main source of difficulty and reading comprehension secondary (15 and 12 items). Results were analysed separately for each of nine language groups, with a total of 11,290 subjects in all. Factor analysis of the TOEFL suggested two factors related to (a) the Listening Comprehension section, and $(b)$ the non-listening subsections. The data did not clearly reveal the expected differential relations between the MC cloze categories and subsections of the TOEFL, though tendencies were apparent and analyses on the whole revealed substantial reliability and validity for the $\mathrm{MC}$ cloze items.

90-155 Henning, Grant (Educational Testing Service). Meanings and implications of the principle of local independence. Language Testing (London), 6, 1 (1989), 95-108.

This paper reviews a variety of definitions of local (conditional) independence presented in the testing literature. An attempt is made to clarify and differentiate among conflicting conceptualisations of this fundamental measurement principle. In particular, it is argued that local independence, 
undimensionality, and non-invasiveness are important but distinct concepts that may, but need not necessarily, overlap. Methods of testing for the presence of local independence in several of its conceptualisations are also presented.

\section{0-156 Lee, Barbara (National Foundation for Educational Research). Classroom- based assessment - why and how? British Journal of Language Teaching, 27, 2 (1989). 73-6.}

This article discusses some of the assessment implications surrounding the introduction of the GCSE and graded objectives schemes, particularly in the regular monitoring of oral performance. Examples are drawn from the MODLS project. In basic terms, external assessment via tests or public examinations fulfills a summative rather than formative role, the latter being an area of special concern to teachers and with which they need to be involved. It is felt that some forms of assessment could be closely integrated with the learning process itself, and actually motivate pupils by providing short-term competence goals.

An illustrative oral exercise is then described, wherein pupils prepare/practise and perform a set task in Spanish together. This developmental, 'joint' approach allowed them to demonstrate their skills/knowledge as a culmination of their previous work. Assessment criteria included 'Communication ', 'Understanding', 'Accuracy' and 'Authenticity', and focused ultimately upon three main concerns: knowledge, skills and attitudes.

Excessive paperwork can be avoided through the use of standard formats and the use of wordprocessors for the production/updating of records and student reports. There is also a need for the development of comprehensible, user-friendly selfassessment schemes.

\section{0-157 Oscarson, Mats (Gothenburg U.). Self-assessment of language} proficiency: rationale and applications. Language Testing (London), 6, 1 (1989), $1-13$.

Learners traditionally view assessment in two distinct ways: (a) as an internal/self-directed activity or $(b)$ as something achieved via examinations and tests given by an 'outside agent'. This article outlines the case for self-assessment in language teaching/learning, in formative rather than summative contexts.

Though self-assessment has achieved prominence recently, it has been felt that the unreliability of subjective estimates of language proficiency represent a major limitation. However, research (e.g. Holec, 1988) would seem to contradict this received wisdom, particularly in cases where the learner has been given training in self-observation and assessment. The learner has a special insight into the effectiveness of teaching programmes, which cannot be ignored. Self-assessment also encourages a raised level/increased sophistication of learner awareness, and a sharing of the assessment burden.

Various evaluation techniques and materials are discussed [examples], including pupil progress cards, questionnaires, rating scales and checklists, learning diaries and log books. A CRAPEL project involving the use of video/audio cassettes in the self-assessment of oral skills is also described.

\section{0-158 Sarig, Gissi (Open U. of Israel and Ramat Aviv Kibbutzim Teachers Coll.). Testing meaning construction: can we do it fairly? Language Testing (London), 6, 1 (1989), 77-94.}

Variations in readers' content schemata explain why different readers may construct different meanings for a given text and still be in the right. When aiming to reflect this meaning relatively in meaning construction tests, test developers may face theoretical, ethical and practical questions: Are any limits on the free interpretation of a text justifiable? If so, what are these limits? If these limits are set, how can they be reflected in a fair, objective and feasible reading test? Following principles emerging from work by Van Dijk \& Kintsch and Alderson \& Short, a meaning consensus criterion answer (MCCA) is suggested as a basis for a relative meaning reading comprehension test. The MCCA is derived from analyses of model answers of a sample of readers from diverse professional backgrounds and levels of expertise. Thus, the MCCA represents both essential, full-consensus components of text meaning, as well as partial, but still considerable, consensus components. It is recommended that the MCCA be used as a basis for item scoring in order to ensure a more feasible objective, yet more relative and, 
therefore, an unbiased tool for the testing of meaning construction. The paper includes a discussion of the theoretical rationale for the MCCA, and a detailed and an exemplified report on the procedures the
MCCA involves. A discussion of MCCA reliability, interconsistency, discrimination power and score meaning follows, and suggestions for future research are made.

90-159 van Lier, Leo (Monterey Inst. of International Studies). Reeling, writhing, drawling. stretching, and fainting in coils: oral proficiency interviews as conversation. TESOL Quarterly (Washington, DC). 23, 3. (1989), 489-508.

This article provides a detailed examination of the oral proficiency interview and its underlying assumptions of validity and value. An attempt is made, by looking at the interview from the inside, to understand what OPIs are and what the participants in them do. The similarities and differences between interviews and conversations are examined, and some of the major problems of proficiency interviewing are illustrated and discussed. Finally, some specific proposals are made that may lead to more effective oral interviewing procedures.

\section{Curriculum planning}

90-160 Corson, David (Massey U., New Zealand). Foreign language policy at school level: FLT and cultural studies across the curriculum. Foreign Language Annals (New York). 22, 4 (1989), 323-38.

This article is written with two audiences in view: the teacher of foreign languages who is interested in the relationship between the foreign language curriculum on the one hand and matters of school administration, policy and management on the other; and the school admistrator or policy maker who is interested in the role and place of the foreign language curriculum in policy and planning at the school level. The article includes: an introductory treatment of relevant factors in successful foreign language teaching and learning that might be pertinent to the design of school policies; a list of foreign language policy questions that a policy making group might need to consider in its planning; an update on what we mean by the phrase 'communicative competence'; and some suggestions as to how cultural studies related to foreign languages might be included across the curriculum. The article also includes a specimen foreign language policy which has been deleveloped as one in a series of 'language policy' case studies in schools of various kinds.

\section{Course/materials design}

90-161 Batstone, Rob. Teachers and course design: the case for a modular approach. ELT Journal (Oxford), 42, 3 (1988), 185-95.

Foreign language course design is not, perhaps, the thriving issue that it once was. Following considerable activity in the 1970 s, interest has turned more to questions of methodology, and to approaches where the learners' conscious attention is on 'meaning-focused activities', where little or no specific attention is paid to language form. There seems to be growing disenchantment with more traditional course designs, containing layers of linguistic specifications, often sequences and integrated by the course designer in a way which can severely limit the teachers' scope for responding flexibly to student needs. This article, addressed to teacher trainers and course designers as well as to teachers, compares this more traditional approach with a 'modular' framework, devised by the author for the British Council Teaching Centre in Cairo. A modular framework stands somewhere between the traditional (syllabus-oriented) and the 'meaningfocused' (methodology-oriented) approaches, by giving the teacher some of the responsibilities traditionally allocated to the course designer. 
90-162 Canesco, Grace and Byrd, Patricia (Georgia State U.). Writing required in graduate courses in Business Administration. TESOL Quarterly (Washington, DC). 23, 2 (1989). 305-16.

The increasing proportion of graduate students to undergraduate students in ESL academic preparation programmes in the United States suggests that more information is needed about language use in graduate courses. This article reports on the characteristics of writing assignments found in syllabuses for graduate courses in business. First, the types of writing assignments and the vocabulary used to label those assignments are analysed and discussed. Second, the use of 'prompts' to guide the writing of the assignments is examined. Finally, implications are suggested for ESL writing courses for non-native speakers who are planning to enter (or already attending) U.S. graduate degree programmes in business.

90-163 Delecroix, Michel ( $U$. of Reims). Guidage en compréhension de l'anglais oral et écrit. [Guidance in the comprehension of oral and written English.] Langues Modernes (Paris), 83, 2 (1989), 60-8.

Most listening comprehension materials test rather than teach, with little analysis of the sub-skills required. This article describes guidance materials recently produced and piloted with the aim of helping learners to introspect upon, evaluate and improve their own listening comprehension strategies. Such materials must be non-prescriptive, recognising differences between learners and the need to find out for oneself what works best.
The system proposed involves listening to passages three times with certain activities suggested before, after and at each point in the process. The emphasis is on active listening, moving from the known to the unknown, and concentrating on key words. Some learners and teachers who tried the approach initially found it rather cumbersome, but after practice opinions become more favourable.

90-164 Graci, Joseph P. (Harvard U.). Are foreign language textbooks sexist? An exploration of modes of evaluation. Foreign Language Annals (New York), 22, 5 (1989), 477-86.

This paper discusses non-sexist guidelines that have been established by publishing houses and some preliminary research on sexism in educational materials. Research (the data are 20 studies conducted between 1975 and 1984) on sexism in foreign language textbooks is then reviewed and critically compared. The relatively sparse and dissimilar body of research identifying and assessing gender role portrayal in FL textbooks underscores the need for more analyses. The unsystematic nature of the research on sexual bias demonstrates the need for a standardised evaluative instrument, so that a data base of similarly analysed FL textbooks can thus be generated.

\section{0-165 Florent, Jill (Heinemman Educational Books) and Walter, Catherine. A} better role for women in TEFL. ELT Journal (Oxford), 43, 3 (1989), 180-4.

Some problems encountered by the second-named author in trying to produce non-sexist (and nonracist) materials for EFL are discussed : these include unconscious stereotypes, and the fact that students and teachers will expect to see a true reflection of the culture of English-speaking countries (i.e. it is not representative to show only minority aspects of society). Publishers, designers, etc, influence the final product, and need reminding to avoid gender bias.

From the editorial viewpoint, no-one wants to be sexist, but sexism is deeply engrained in our culture. It can occur at many different levels in the production of a textbook: words and syntax, images, content, and in the perception of the user. 


\section{Teacher training}

90-166 Moeller, Paulette (U. of Regina, Canada). French student teachers: who knows how good they really are? Canadian Modern Language Review (Toronto), 45, 3 (1989), 445-56.

The author proposes the establishment of a national assessment centre that would have the authority to develop, administer, and evaluate FSL teacher competencies, and issue a national certificate over and above provincial certification. The author proposes that FSL certification is now a national issue and must be examined at the national level if it is to do justice to today's student teachers.

90-167 Trafford, John ( $U$. of Sheffield). Meeting the challenge: an account of the training of a blind language teacher. Modern Languages (London), 70, 3 (1989). $150-5$.

This article provides an account of the training of a blind student, Nicola Mathews, who completed a PGCE course in French and German at the University of Sheffield. After acceptance of her application, forward planning proved necessary, both in practical terms such as brailling or taping course materials, and in arrangements for teaching practice placements. Support was forthcoming from the Royal National Institute for the Blind. It became clear that the range of visual handicaps is enormous and individual needs differ widely: it is best not to make assumptions about what may or may not present problems. A blind teacher's marking is done through 'personal readers' who work under the teachers' supervision. Blackboard work is replaced by the overhead projector, with acetates prepared in advance by the personal readers. Classroom discipline is achieved principally by good rapport with the pupils, who seemed unwilling to 'take advantage'. Reticent pupils pose more of a problem, but this can be solved by means of questioning techniques, extra attention, etc. Some pratical problems which might arise include the difficulty of using visual aids, authentic materials and newly published materials, and job-hunting (though the latter was not a problem for Nicola). In general, the Department found the experience of training a blind student teacher very positive.

\section{Teaching methods}

\section{0-168 Beretta, Alan. (Michigan State U.). Attention to form or meaning? Error treatment in the Bangalore Project. TESOL Quarterly (Washington, DC), 23, 2} (1989). 283-303.

This article reports an evaluation study of the Bangalore project, a content-based approach to language learning. It examines the question, Do teachers attend to meaning or to form, and is such a distinction observable in classroom practice? The study investigated the way that error treatment in Bangalore classrooms was realised in practice in a sample of 21 lesson transcripts. It was found that the treatment of linguistic error was largely consonant with the project's statements about the kinds of attention that are appropriate to a focus on meaning and that this could be distinguished from the ways of treating linguistic error that are attributable to a focus on form. However, the most likely explanation for this finding is that as the project developed, task types were selected that would curtail learner production and, thereby, the risk of making linguistic error. This finding has implications for teachers interested in content-based curricula.

\section{0-169 Bonnet, Philippe (IUT de Villetaneuse - U. of Paris Nord) and Arrouays,} Michel (ENS Fontenay - Saint-Cloud). Le maintien de l'acquis dans la formation d'adultes. [Language maintenance in adult learners.] Langues Modernes (Paris), 38, 5 (1989). 15-20.

Executives and professional people rarely need to make immediate and continual use in their work of the languages they have studied. Though usually of higher-intermediate standard (or else the notion of language maintenance would be devoid of meaning), they tend to underestimate their own language 
skills. They need first of all some concept of what a language is and how it functions. Motivation and a feeling of being responsible for their own learning are also essential prerequisites.

A language maintenance programme may be offered by the workplace (films, lectures, intensive weekends, etc.) or may be devised jointly by trainer and student, to meet individual needs and with a greater or lesser degree of learner autonomy. Rather than thinking in terms of a set amount of knowledge and skills to be acquired, learners need to be helped to formulate their own strategies for language acquisition to become aware of the learning process, and to assess for themselves their own progress.

\section{0-170 Burnaby, B. and Yilin Sun (Ontario Inst. for Studies in Ed.) Chinese teachers' views of Western language teaching: context informs paradigms. TESOL Quarterly (Washington, DC), 23, 2 (1989), 219-38.}

This article reports the views of 24 Chinese (People's Republic of China) teachers of English on the appropriateness and effectiveness of 'Western' language-teaching methods (here defined according to Canale \& Swain) for use in Chinese situations. The Chinese teachers believed that the communicative approach was mainly applicable in China only for those students who planned to go to an English-speaking country, and, as non-native speakers, they noted their limitations with respect to the sociolinguistic and strategic competence in English that is required for using this approach effectively. The teachers also cited various con- straints on implementing Western language-teaching methods, including the context of the wider curriculum, traditional teaching methods, class sizes and schedules, resources and equipment, and the low status of teachers who teach communicative rather than analytic skills. An examination of these views in light of the context and theory of Western language teaching demonstrates that the Chinese teachers' concerns have considerable justification. Various suggestions are made as possible means of adapting Western language-teaching methods to the situation in China.

90-171 Caré, Jean-Marc (CIEP Belc, Paris). Approche communicative: un second souffle? [The communicative approach: second wind?] Français dans le Monde (Paris), 226 (1989), 50-4.

The communicative approach is in a crisis because of the problem of authenticity and bringing reality into the classroom. A solution is proposed in which pupils progress from dramatisation through simulation to improvisation. Dramatisation uses a textbased dialogue and students learn and act the parts; simulation progresses in three stages from the more guided (an entirely predictable situation), through a less predictable, but still controlled situation (e.g. wrong dates on a reservation) to much more broadly-based situations (e.g. a block of flats, an island, a circus, a village) that range from the nearreal to the entirely imaginative. In improvisation all support is removed and students are responsible for their language and how they use it (even beginners can improvise).

It is hoped that this approach will take communicative teaching towards a more pragmatic (in the linguistic sense) concept of language learning.

90-172 Chun, Dorothy M. (U. of Texas at Austin). Teaching tone and intonation with microcomputers. CALICO Journal (Provo, Utah), 7, 1 (1989), 21-46.

Although research on the use and effectiveness of visual feedback for teaching tone and intonation began more than 30 years ago, the technology for signal analysis and pitch extraction using microcomputers has only recently become widely accessible and affordable. This paper (1) reviews the major pedagogical applications of acoustic phonetic research for teaching segmentals (individual sounds) and suprasegmentals (intonation, stress, rhythm); (2) summarises the hardware and software currently available for speech analysis on the Macintosh and IBM-PCs, and (3) discusses courseware features that should be included in implementing this new technology to help foreign language students improve their production and perception of tone and intonation. 
90-173 Elkabas, Charles. L'enseignement des langues assisté par ordinateur: nouvelle pédagogie? [Language teaching aided by computer - a new approach?] Canadian Modern Language Review (Toronto, Ontario), 45, 2 (1989), 258-70.

At a time when language specialists and educators are placing greater stress on the use of language as a tool for communication, much recent educational software is taking computerised teaching back several years by focusing almost exclusively on the structures and forms of language and on programmed learning instead of developing communicative skills. The massive shift to computerised language teaching therefore risks leading to an overfragmentation and too-rigid standardisation of the language thus presented. Through an examination of the different means of testing and correcting which computer-assisted language instruction (CALI) offers, and through an analysis of their pedagogical approach, the drawbacks as well as the dangers of programmed learning are underlined; its apparent technological advancement notwithstanding, the latter is still based on traditional structural and mechanical principles. As long as artificial intelligence does not drastically change these old behaviourist principles, CALI can only play a minor role in language teaching.

\section{0-174 Faltis, Christian J. (U. of Nevada). Code-switching and bilingual} schooling: an examination of Jacobson's new concurrent approach. Journal of Multilingual and Multicultural Development (Clevedon. Avon), 10, 2 (1989), 117-27.

This article describes the New Concurrent Approach to bilingual instruction. This approach systematically incorporates inter-sentential code-switching as a means for teaching content to limited English proficient children raised in a bilingual environment. The article examines how code-switching present in bilingual communities has been incorporated and adapted for instruction, and how the adaptation contributes to the balanced distribution of the two codes in question. Reference is also made to major fears commonly associated with the use of codeswitching for instructional purpose, and presents evidence to show that these fears are largely unfounded.

\section{0-175 Harley, Birgit (Ontario Inst. for Studies in Ed.). Functional grammar in} French immersion: a classroom experiment. Applied Linguistics (Oxford), 10, 3 (1989), 331-59.

The role of grammar teaching in promoting communicative competence among classrom L2 learners is a much-debated issue. In this experimental study, the effect of a functional approach to grammar teaching is examined in the context of French immersion classes at the grade 6 level. The students are provided with focused input in a problematic area of French grammar and with increased opportunities for meaningful production of the relevant target forms. In a pre-test, immediate post-test, delayed post-test design, immersion classes who are exposed for an eight-week period to an experimental set of teaching materials are compared with other immersion classes who do not receive the experimental treatment. Findings indicate that at the end of eight weeks, with adjustment made for pretest scores, the experimental classes outperform the comparison classes on two out of three immediate post-test measures. Three months later, however, there are no significant differences between the two groups. These findings are interpreted in relation to questionnaire feedback from the teachers and classroom observations.

\section{0-176 Jacobs, George ( $U$. of Hawaii). Miscorrection in peer feedback in writing class. RELC Journal (Singapore), 20, 1 (1989), 68-76.}

After a brief survey of the literature on peer feedback, a study is described in which miscorrection in group writing activities was investigated. Correction was focused on grammar only and corrections were of two types: an item thought to be incorrect was corrected, or where there was uncertainty, the item was only circled.
The results showed that: (1) most of the marking too the form of accurate correction of incorrect forms (this was boosted when added to markings indicating uncertainty about the correctness of the original), and (2) changes in a second version of the writing were largely selected from the same areas as in (1). Moreover, most inaccurate corrections of 
correct versions in the original were not incorporated in changes in the second version.

The findings of the study are consistent with studies of miscorrection in spoken activities, and show how peer feedback can have a role in the development of writing ability. Suggestions are made as to (a) other ways of investigating miscorrection in peer feedback, $(b)$ other forms of peer feedback beside the marking of errors, and $(c)$ how to make feedback more effective.

\section{0-177 Kelly, Peter (Facultés Notre-Dame de la Paix. Namur). Utilisation of the} hookword method for the learning of Polish vocabulary: a personal investigation. ITL (Louvain, Belgium), 85/6 (1989), 123-42.

The hookword method of learning foreign language vocabulary, evolved by Paivio (1979), is a more complex mnemonic device than the better-known keyword method, evolved by Pressley and his associates in the early '80s. While the keyword method teaches FL vocabulary to recognition level, the hookword method aims for productive use - in this respect it is more ambitious. A number/letter code is first established, in which the cardinal numbers 0 to 9 stand for the consonant sounds in the target language. There is a link between the consonant and its number, e.g. $t$ is a single stroke, so is paired with 1 ; $n$ is composed of two strokes, so is paired with $2 ; 1$ is roman 50 , so is paired with 5 . The next stage consists of learning a list of pegwords in the target language which can be attached to each number, e.g. thé (attached to 1), noeud (attached to 2), loi (attached to 5). The same pegword can be used for several items; the pegwords themselves are kept below 100 to make their learning a manageable task. The final stage consists of hooking vocabulary items to be learned onto the pegwords by means of mental images.

Paivio and Desrochers found this method to be three times more effective than the rote rehearsal method for recalling French nouns, and twice as effective for remembering them one day later. The author found the method simpler to operate than expected when he applied it to the learning of Polish vocabulary.

90-178 Lewis, C. and Shapson, Stan M. (Simon Fraser U., Canada). Secondary French immersion: a study of students who leave the programme. Canadian Modern Language Review (Toronto), 45, 3 (1989), 539-48.

This study compares the opinions and attitudes of students who have transferred from secondary French immersion with those who have stayed. Students in four British Columbia school districts who had transferred from immersion between grades 8 and 11 were matched with students still in the programme. Results revealed that the most significant factors in transfer students' decision to leave the programme were dissatisfaction with the quality of instruction and the content of the immersion courses, the degree of difficulty of the courses and the notion that better grades would be obtained in the English programme. Comparisons with the students still in the programme reveal that significantly more immersion students believe that a bilingual education will lead to better job opportunities and that the bilingual programme provides a better education. Recommendation arising from the study and implications for further research are discussed.

\section{0-179 Liebelt, Wolf. Anregungen für den Umgang mit Video im} Fremdsprachenunterricht. [Ideas for the use of video in foreign language teaching.] Praxis des neusprachlichen Unterrichts (Dortmund, FRG), 3 (1989), 250-61.

All too often videos are seen by both teachers and pupils as a relaxing end-of-term activity and little use is made of the potential offered by the controls on a video recorder. An active approach to video starts before the video is shown and continues after, and can be enhanced by making audio copies, which can be made available to groups or individual pupils. The aims of activities may be divided into linguistic, area studies, film aesthetics, and literary study, and the film used as both an information text and a language text. It is not neccessary for pupils to understand the video fully. A number of examples are presented with illustrations: (1) how to prepare pupils, especially by showing stills or short scenes in advance; (2) ways the controls can be used for setting tasks during the showing of the film; and (3) possible follow-up exercises. 
90-180 Lindholm, John. The use of delayed audio feedback in learning pronunciation of a second language. IRAL (Heidelberg. FRG), 27, 3 (1989), 236-9.

The author hypothesises that the inability of adults to learn the pronunciation of a second language is due to the masking of atmospherically conducted vocal feedback by bone-conducted feedback. If the ears of a subject could be moved outside his head so that he could hear himself simply as others hear him, he would automatically begin to modify his pronunciation to correspond to that of native speakers. This effect was simulated by electronically delaying each atmospherically conducted stimulus until the perception of the corresponding boneconducted stimulus had concluded. The author feels that results obtained using this technique in his study of German are positive enough to justify further evaluation of the hypothesis and of the efficacy of the delayed-feedback apparatus, which he refers to as an 'Ear Mirror.'

\section{0-181 Marsh, Stella (New Coll., Durham). Schools-industry links in the North East. British Journal of Language Teaching, 27, 2 (1989), 77-80.}

A pilot project, 'EUROLINKS 1988', was launched in order to bring together schools and industry in the field of foreign languages in a practical way. Fifth-form GCSE pupils and teachers, advisers and careers officers spent the day investigating ways of promoting the North East and its companies and products to European partners or customers. They were joined by representatives from business and industrial organisations which already have extensive trading links with Europe and beyond. Pupils were shown how their foreign language studies at school relate increasingly to the world of work and the prosperity of the region and the country as a whole. They were made aware of the impending impact of the single European market and the significance of the preparations for 1992. One of the principal messages of the day was the insistence on the fact that foreign language skills are becoming increasingly important as an ancillary qualification in a wide range of jobs at all levels. Other curriculum areas encompassed were communication skills, environmental and economic awareness, business studies, careers opportunities and information technology.

\section{0-182 Pennington, Martha C. (U. of Hawaii at Manoa). Teaching} pronunciation from the top down. RELC Journal (Singapore), 20, 1 (1989), 20-38.

Pronunciation is re-examined from a 'top-down' perspective which shifts the focus of attention in language instruction from individual phonemes to suprasegmentals and other features of the larger context of utterances. These include prosody, phonological fluency, voice quality, and gestures. A basis is provided for instruction and student practice of the entire communicational complex in which pronunciation is situated.

\section{0-183 Pitts, Michael and others (Los Angeles Community Coll.). Acquiring} second-language vocabulary through reading: a replication of the "Clockwork Orange' study using second-language acquirers. Reading in a Foreign Language (Oxford), 5, 2 (1989), 271-5.

Adult second-language acquirers were asked to read sition of nadsat words. This result replicates Saragi the first two chapters of $A$ Clockwork Orange, a et al.'s findings for native speakers of English and novel containing a number of slang words of confirms that adult second-language acquirers can Russian origin ('nadsat' words). Subsequent testing acquire vocabulary from reading. revealed modest, but significant incidental acqui-

90-184 Quetz, Jürgen. Ist Grammatikunterricht noch zeitgemäß? [Is grammar teaching still relevant?] Praxis des neusprachlichen Unterrichts (Dortmund, FRG), 3 (1989), 303-12

The author examines existing studies of the usefulness of grammar learning, with particular ref- erence to Krashen's dichotomy between 'learning' and 'acquisition'. Krashen's model is rejected as 
based on too narrow a definition of 'learning' and a lack of clarity with regard to the process of acquisition. A more plausible model of learning and acquisition is that of Seliger (1979) who sees grammar rules as 'acquisition facilitators', which focus the learner's attention on critical aspects of the language that need to be induced. In the absence of any research specifically comparing the speech production of successful 'learners' with successful 'acquirers' in authentic communication situations, the author concludes that, whilst it is unclear whether traditional grammar teaching is beneficial, a modern communicative approach including gram- matical explanations is almost certainly helpful, at least in speeding up the process of acquisition. If, following Klein (1984), the brain is considered to have a single language processor which analyses new information about language in relation to the general and specific information it already possesses, it is the teacher's task to adapt the input (grammatical explanations) accordingly. Explanations should be brief, structured and simple, with a basis being laid in early years for later development. They should take their place alongside practice and the creative use of language as just one of the elements of language teaching.

\section{0-185 Richardson, lan M. (King Saud U.). Translation and interpretation. British Journal of Language Teaching. 27, 2 (1989), 83-7 and 94.}

In second or foreign language learning, communication shortcomings are frequently due to the fact that priority has been given to learning the grammatical system of the language rather than to comprehension of the meaning of an utterance or text. Thus a distinction is drawn between 'translational' meaning and 'interpretative' meaning, the former referring to word for word comprehension, the latter to gist comprehension.
The 'interpretation' 'method of teaching a foreign language, with meaning being reconstructed by inferring blanks, should always precede the 'translation' method. Receptive skills which are essential in language acquisition can be developed by training in summary and paraphrase exercises.

90-186 Rings, Lana (U. of Texas at Arlington). Cultural meaning and structure in conversations and their pedagogical implications. Foreign Language Annals (New York), 22, 5 (1989), 459-68.

As teachers of foreign language are becoming more aware than ever that language form, function, and cultural meaning are integrally linked, two questions arise which demand our attention; how are form, function, and meaning interconnected within target language texts, and how can knowledge of structure and meaning interrelationships be conveyed to students? To these ends, this article examines features of a German conversation, which illustrate some of the connections. It then explores the pedagogical implications through suggested first-year classroom activities.

\section{0-187 Romney J. C. and others ( $U$. of Calgary). The effects of reading aloud to immersion children on second language acquisition. Canadian Modern Language Review (Toronto), 45, 3 (1989), 530-8.}

In order to assess the effects of reading aloud in French to immersion school children on some of their language skills, 58 children (54 after attrition) in Grade 2 classes were allocated at random to an experimental group, which was read stories in French for half an hour each day at school for three months, and a control group, which followed the normal language arts curriculum instead during that time. The two groups were tested before and after the intervention on Barik and Swain's Test de lecture, the Peabody Picture Vocabulary, and improvised free association and free recall tasks. The findings showed that reading aloud in French is a simple and effective adjunct to formal teaching methods for accelerating second-language acquisition. 
90-188 Schmidt, Herminio. Real conversation as a motivational factor through interactive video. Canadian Modern Language Review (Toronto. Ontario), 45, 2 (1989), 329-38.

Favourable attitudes towards a language do not reflect motivation alone. Motivation must be linked with effort and drive in order to trigger real achievement. This article shows how students' efforts and drive are optimised in an interactive 'real conversation' video approach to learning. Some pros and cons of the interactive videodisc system are discussed as they relate to language instruction. The results of the first Canadian field-tested interactive video for language learners demonstrate how simple technology - if used properly - can increase the students' motivation, effort and drive.

\section{0-189 Snow, Marguerite Ann and others (California State U.. Los Angeles) \\ A conceptual framework for the integration of language and content in second/foreign language instruction. TESOL Quarterly (Washington, DC) , 23, 2 (1989), 201-17.}

This article proposes a conceptual framework for the integration of language and content teaching in second and foreign language classrooms. In this model, language and content teachers work collaboratively to determine language-teaching objectives. These objectives derive from two considerations: (a) content-obligatory language (language essential to an understanding of content material) and (b) content-compatible language (language that can be taught naturally within the context of a particular subject matter and that students require additional practice with). The conceptual framework is illustrated in four instructional settings - the mainstream class, the ESL class, the foreign language immersion class, and the FLES (Foreign Language in the Elementary School) class. General implications for the integration of language and content teaching are also discussed.

\section{0-190 Spolsky, Ellen. 'I come to bury Caesar, not to praise him': teaching resisting reading. ELT Journal (Oxford), 43, 3, (1989), 173-9.}

One of the reasons why cannonical literary texts are included in the English curriculum is that they help students to understand the cultural experiences and values of the foreign culture whose language they are learning. It is important, however, that students learn not only to understand the values of others, but, as well, to summon up their own experiences and values for comparison and, where necessary, to resist the imposition of values. The teaching of James Joyce's short story, 'Eveline', in Israeli high schools exemplifies how students can be brought to devalue their own experience in learning about another culture. Teaching resisting reading, as feminist literary critics have shown, is a way of ensuring that learning another's culture does not lead to the destruction of one's own identity.

\section{0-191 Vigner, Gérard (Mission française de coopération, Yaoundé, Cameroun). Les techniques de guidage dans les tâches complexes. [Guidance techniques in complex tasks.] Langues Modernes (Paris), 83, 2 (1989), 18-36.}

It is relatively easy to provide models and detailed guidance for tasks on the levels of spelling, grammar, etc., much harder for such tasks as commenting on a text or contributing to a debate. Such guidance involves breaking up and perhaps simplifying the task, but without losing sight of its global coherence.

The examples given consist of tables and diagrams which set out functions or notions and their linguistic realisations. These guide the learner in the use of devices such as concession and justification in logical argument, or persuasion and dissuasion in debate, and in recognising textual functions in criticism. A table is presented of all the stages in language production - planning, choice of content, choice of text type, putting into words - and of the interventions and learning tasks appropriate at each stage. 
90-192 White, Cynthia J. Negotiating communicative language learning in a traditional setting. ELT Journal (Oxford) 43, 3 (1989), 213-20.

In motivating students to learn English through a more communicative approach it is important to The language-teaching circumstances outlined in take into account habitual learning styles, aspects of this article are located in China with a part-time language which are seen as significant and attitudes adult class of varying background and proficiency. to less formal teaching. Confidence can be developed in new ways of learning and using language through a skilful combination of meaningful tasks which provide learners with individual feedback on their performance, and in which both individual and collaborative activities are seen to be an integral part An indigenous means of communication, namely wall posters, was transferred to the classroom and used as a basis for an extended session of fluencyfocused activities, through which students became independent uses of the language they had acquired. 